\title{
A comparison of floor surfaces for injury prevention in care settings: impact forces and horizontal pulling force required to move wheeled equipment
}

Authors:

*Bethany E Keenan, $\mathrm{PhD}^{1}$; Kevin Hallas, BSc (hons) Chem²; Amy K Drahota, $\mathrm{PhD}^{3}$ and Sam L Evans, PhD ${ }^{1}$

\section{Affiliations:}

${ }^{1}$ School of Engineering, Cardiff University Queen's Buildings, The Parade, Newport Road, Cardiff, CF24 3AA, UK

${ }^{2}$ Science Division, Health \& Safety Executive (HSE), Harpur Hill, Buxton, Derbyshire, SK17 9JN, UK

${ }^{3}$ School of Health \& Care Professions, University of Portsmouth, Portsmouth, Hampshire, PO1 2PR, UK

Corresponding Author:

Dr Bethany E Keenan

School of Engineering

Cardiff University

The Parade

Cardiff

CF24 3AA

Tel: $+44(0) 2920687650$

Email: keenanB@cardiff.ac.uk

Kevin Hallas: kevin.hallas@ktn-uk.org

Amy Drahota: amy.drahota@port.ac.uk

Sam L Evans: evansSL6@cardiff.ac.uk 


\section{Mini Abstract}

Shock-absorbing flooring is one potential solution to prevent fall-related injuries. No standards exist to characterise shock-absorbing healthcare flooring. This study explores two mechanical tests for impact force reduction and horizontal force required to move wheeled objects. An appropriately designed rubber underlay can reduce peak impact by $25 \%$ compared to $1 \%$ with standard vinyl.

\section{Abstract}

\section{Purpose}

Severe falls often occur in hospitals and care homes. Shock-absorbing flooring is one potential solution to prevent fall-related injuries; however, no standards exist for characterising flooring as an injury prevention measure. Shock-absorbing flooring use in high risk settings may influence both patients (injury-saving potential) and staff (manoeuvring equipment). We aimed to explore two tests to characterise floors, to determine shock-absorbency and horizontal pulling force required to move wheeled objects.

\section{Methods}

Mechanical testing was performed according to the Canadian Standards Association Z325 Hip Protectors document. This test was developed for hip protectors but is applicable to compliant surfaces that form part of the floor. Tests were performed on commercially available floor materials (suitable for care settings) to assess the force required to initiate movement of a wheeled object across the floor. We explored the relationships between horizontal force required to pull wheeled objects, impact force, floor thickness and core material.

\section{Results}

Considerable differences were identified between floor samples in their ability to reduce the peak impact force (range $0.7-25 \%$ ). A peak force reduction of up to $25 \%$ can be achieved with a specially designed rubber underlay. Horizontal pulling force increased with floor thickness but was lower for rubber floors. There was no direct relationship between impact attenuation and horizontal pulling force. Whilst thickness and core material explain some variation (66.5\% for wheel movement; $82.3 \%$ for impact), other unmeasured factors clearly influence floor performance.

\section{Conclusions}

These results can inform the development of flooring and the establishment of standards needed to underpin practice, research, and development in this field.

\section{Keywords}

Biomechanics, Floors, Falls, Fall injuries, Hip Fractures, Prevention 


\section{Introduction}

Falls and fall-related injuries are a high-impact, high cost public health concern and are the second leading cause of accidental or unintentional injury deaths worldwide [1].Older adults are at greater risk of both falls and fall-related injury [2][3][4], with fragility fractures carrying a high risk of nursing home admission [5], and increased mortality [6]. The impact of falls is compounded in those with osteoporosis, particularly women, who are more susceptible to osteoporosis post-menopause. Osteoporosis is estimated to affect 200 million women worldwide, with 1 in 3 women (and 1 in 5 men) over the age of 50 experiencing an osteoporotic fracture in their lifetime [7][8][9]. Hip fractures are one of the most common fragility fractures in elderly populations, accounting for 1.8 million hospital bed days and £1.1 billion in hospital costs every year in the United Kingdom, excluding the high cost of social care [10][11]. Examples of associated healthcare costs for hip fractures internationally are estimated to be $\$ 34$ billion in the United States [11], with the economic burden of both incident and prior fragility fractures estimated at $€ 37$ billion in the European Union [12]. Each injurious inpatient fall in Australia is associated with an estimated additional AUD\$4,727 of hospitalisation costs compared to a non-injurious fall, and there have been calls for prevention efforts to target the most severe falls [13].

Wearable hip protectors aim to reduce peak force at the proximal femur upon impact. Their effectiveness to date has been questionable, largely due to issues of practicality, user compliance and comfort [14]. However, a recent retrospective cohort study reported an approximate 3-fold reduction in the risk of hip fractures during falls protected by a hip protector versus unprotected falls, for individuals at fourteen long term care centres [15]. Hip protectors were worn in 2,108 of 3,520 cases $(60 \%)$, where patients recorded falls. Furthermore, osteoporosis can lead to fall-related fragility fractures in other skeletal locations, such as the spine and wrist. Fall-related traumatic brain injuries are another common and serious type of fall-related injury whose incidence is increasing over time. Schonnop et al., reported $37 \%$ of falls in long-term care residents involve head impact, usually onto a vinyl or linoleum floor [16]. An alternative method for preventing fall-related injuries which may help to avoid these problems could be the use of shock absorbing flooring [17].

The use of flooring for injury prevention in healthcare settings is an emerging field of study; research of clinical effectiveness to date has mixed indications and remains largely inconclusive with a focus on only a few select products [17][18][19]. To help resolve these uncertainties, a systematic review of clinical and economic evidence is currently underway [20]. A fundamental challenge for the field, particularly with regard to hospital settings, is identifying a suitable flooring product, which has sufficient shock absorbency to reduce the impact from a fall, and which simultaneously maintains an 'ecological fitness' for clinical use, in terms of installation, cleanliness, durability, and practicality (e.g. for pushing and pulling wheeled objects across it). It is also necessary to ensure that floor surfaces are not only effective in attenuating impact force during a fall, but also minimise potential impairments in balance and mobility. Previous studies investigating low stiffness floors have found that some novel shock-absorbing floors attenuate femoral impact force by up to $50 \%$, without significantly impairing mobility and balance control responses, compared to simple foam surfaces which can alter gait mechanics, and decrease the quality of sensory inputs provided by the proprioceptive and pressure receptors in the ankle and foot [21][22][23].

Biomechanical testing methods of shock-absorbing flooring vary considerably in the literature and involve either a pendulum design system, pelvis release experiments, an impact transducer dropped through a plastic tube or a drop impact tower [23][24][25][26][27][28][29][30]. The conditions under which these methods are conducted (e.g. human subjects, surrogate pelvis/hip/head form, effective mass, impact velocity, etc) also differ, making objective comparison difficult. Whilst novel shock-absorbing floors are potentially a biomechanically effective strategy for reducing fall-related injuries, there is an 
urgent need for clear guidelines as to how manufacturers should test their product, causing various test methods to be used.

Recently, the Canadian Standards Association (CSA) have written the first edition of CSA Z325 Hip Protectors (which supersedes EXP-08-17 Express Document), to standardise a test method of force attenuation of hip protectors [31]. Whilst the proposed testing method is written in the context of hip protector assessment, here we have used it as a novel basis for comparing flooring products, with a view to extending further standardization to this field. A hospital-based pilot study of shock-absorbing flooring for fall-related injury prevention indicated that the intervention has promising features with regards to potential for injury prevention (yet to be verified by a definitive trial) [32]; however, adverse effects may be present for staff having to wheel heavy objects across the floor, with risk particularly increased in instances where staff are handling equipment in isolation [33][34][35]. There is an important assessment to be made therefore, when selecting a shock-absorbing flooring product, to understand the potential trade-off between impact force reduction and horizontal pulling force required to move wheeled objects.

This study explored the use of two mechanical tests of floor surfaces to determine the protection they offer in the event of a fall, and the force required to move a heavy piece of equipment such as a hospital bed on the floor. We tested commercially available floor materials that conform to current safety standards. The aims of this study were: (a) to assess the force attenuation of different types of flooring products; (b) to investigate the horizontal force required to move wheeled equipment over different types of flooring products; (c) to investigate the relationships between horizontal pulling force, impactforce, floor thickness and core material; (d) to consider the implications of these findings with respect to selecting products for use in hospitals, care homes or personal use for older adults and whether flooring is a possible alternative to hip protectors.

The study was commissioned by the Health and Safety Executive (HSE, Buxton, UK) in order to provide an independent evaluation of possible floor surfaces. It was therefore necessary to anonymise the floor materials so as not to provide a commercial advantage to manufacturers, and thus we have not identified the suppliers in this paper. Details of the construction of each floor and the materials used are given below.

\section{Materials and Methods}

\subsection{Flooring Samples}

The HSE compiled fourteen different flooring samples from five suppliers for testing. The sample range included vinyl and rubber flooring, with some comprising a shock-absorbing foam backing of varying thicknesses (Table 1). Two of the samples were underlays (rather than a complete flooring system) and were combined with overlays for testing. Sample thicknesses (which sometimes vary from nominal thickness data quoted by manufacturers), ranging from $2 \mathrm{~mm}$ to $25 \mathrm{~mm}$ (median=7.0 $\mathrm{mm}$ ), were measured by punching a hole through the sample and using a calibrated gauge to measure the depth of the hole (thus avoiding atypical readings which can be obtained from sample edges). A caliper was then used to measure the thickness of the individual layers of each floor (Table 1). We used the same flooring samples for both the impact and wheel movement testing procedures.

We have broadly categorised the floor samples as 'standard vinyl' (i.e. resilient sheet flooring, not designed for shock-absorbency), 'foam-backed' or 'rubber-backed' vinyl (typically these are sold as sports floors, or acoustic/sound-insulating flooring), and 'novelty health floors' (i.e. something that has been specifically designed for use in care settings as a shock-absorbency measure). It should be noted that within the broad categories (for example 'foam-backed vinyl') floor samples differed in more subtle characteristics (such as in material densities, layering techniques, and surface finishes). Products have been assigned a code to maintain confidentiality. 


\subsection{Impact testing}

The test set-up for the mechanical impact of the flooring has previously been described in an existing study by Keenan et al [36]. A simplified version of the method is given below, but further details can be found in the previous study.

\subsubsection{Test Rig}

Mechanical impact testing was performed according to the CSA Z325 Hip Protectors Documentation: where a mass of $28.0 \mathrm{~kg}$ is released vertically at a velocity of $3.2 \mathrm{~m} / \mathrm{s}$ onto the soft tissue simulant [31]. A drop tower impact system was used to impact the femurform during a simulated fall (Figure 1). A load cell and oscilloscope were used to measure the peak force at the proximal femur. The temperature was recorded as $19.0 \pm 1.0{ }^{\circ} \mathrm{C}$ throughout the test period. Note that the floor samples were not conditioned in a chamber, but testing was carried out in the same environment. Furthermore, it is important to note, that the drop tower impact system is designed to measure the peak compressive force applied to the proximal femur, as opposed to bending and torsional moments and shear forces.

\subsubsection{Drop weight assembly}

In the present study, an Instron Dynatup 9250HV (Instron, High Wycombe, UK) was used. The total mass of the drop weight assembly was $28.05 \mathrm{~kg}$, where the heavy crosshead weighed $16.03 \mathrm{~kg}$, the spring assembly $3.14 \mathrm{~kg}$, and a series of weights, which slotted into the crosshead assembly, $8.88 \mathrm{~kg}$. A velocity measurement system was not possible with the current test rig, and as such the vertical velocity of the drop weight at the point of impact with the floor was not measured.

\subsubsection{Impact plate}

The impact plate was made of carbon fibre and measured $230 \times 180 \times 70 \mathrm{~mm}$. The impact plate was regularly inspected for visual signs of damage. The impact plate remained unchanged for the duration of the testing period. The floor samples were cut to a size of 160 $\mathrm{mm} \times 160 \mathrm{~mm}$ and affixed to the rigid impact plate at the lower end of the spring using doublesided tape. This ensured the floor replicated a flat surface and as such differs to the Standard recommendations where a hip protector is positioned over the soft tissue covering.

\subsubsection{Anatomical femur form and soft tissue covering}

The femur form was constructed from aluminium and made by the mechanical workshop at Cardiff University. The piezoelectric load cell was screwed to the femur form and the base plate, which in turn is rigidly bolted to the base of the machine. For stability, the distal end of the femur is supported by a roller, which acts as a hinge (Figure 1).

The silicone soft tissue simulant covering the aluminium femur form was made using Jacobson Chemicals RTV (room-temperature-vulcanizing) C204 silicone rubber, 81b catalyst and 10\% silicone oil. The silicone was cured in a custom-made mould [36]. The condensation cure silicone was then placed in the oven at $40^{\circ} \mathrm{C}$ and left for three days to fully cure.

\subsubsection{Force measurement instrumentation}

A Kistler piezoelectric load cell, type 9712B5000, maximum load 5000 lbf (approximately $22.24 \mathrm{kN}$ ) was located directly below the midpoint of the greater trochanter to support the femur form. The load cell was connected to an Agilent technologies DSO1072B oscilloscope, $70 \mathrm{mHz}, 2$ analog channels. The load cell was powered by a linear analogue, Farnell E30/1 bench power supply and set to $24 \mathrm{~V}$ throughout the testing period.

\subsubsection{Baseline Force Measurements (Dynamic Calibration)}

Three initial baseline force measurements were conducted and recorded prior to impacting the flooring samples. The drop weight assembly was dropped from a vertical height of $0.5 \mathrm{~m}$ onto the hip form (without a flooring sample) to assess the peak force during a simulated fall. 
A further three baseline force measurements were taken throughout the testing procedure to ensure the baseline remained unchanged.

\subsubsection{Mechanical Testing}

The drop weight assembly was vertically released from a height of $0.5 \mathrm{~m}$ to ensure an impact velocity of $3.2 \mathrm{~m} / \mathrm{s}$ was achieved. The force during impact was displayed on the oscilloscope and recorded as a CSV file which could later be processed in Mathworks, Matlab R2018. The sample was then removed and inspected for visible signs of external damage before repeated tests were performed. Each floor sample was tested three times by the same observer, in keeping with the Standard [31]. There was an opportunity to conduct some additional tests (bringing the total to five trials) for nine of the samples and these data have been included to improve the quality of the results. All tests were conducted on a single day to minimise variation in the testing environment (e.g. temperature) and analysis was carried out post testing.

All tests were recorded with a sampling frequency of $10 \mathrm{kHz}$. A fourth-order Butterworth filter with a cut-off frequency of $37 \mathrm{~Hz}$ was applied to the data (during post-processing) to produce a smooth force-time curve. The maximum value of force on this processed data (in N) is used as the measure of the peak force (in N). Figure 5 shows an example of the force-time graphs produced in Matlab, where the solid blue line represents the raw data and the orange dashed line is the filtered data.

\subsection{Wheel movement testing}

These methods were developed to provide a repeatable and controlled test that is indicative of force applications for the flooring surfaces tested, such as when pushing / pulling a standard hospital bed and occupant with a total weight of $300 \mathrm{~kg}$. When a wheeled object stands on a shock-absorbing floor there will be resistance to movement because the wheel sinks into the floor to a greater or lesser extent. The aim of this test is to measure the force that is needed to move a wheel carrying a typical load over the floor surface.

\subsubsection{Test rig}

A typical single wheel attachment (125 $\mathrm{mm}$ diameter, $27 \mathrm{~mm}$ width) representative of that used for hospital beds was mounted onto a test rig with a moveable carriage below. The sample flooring was positioned on the carriage, such that the castor could be lowered by the rig on to the flooring sample. Two $25 \mathrm{~kg}$ weights were attached to the wheel mounting, which combined with the weight of the rig, applied $748 \mathrm{~N}$ of vertical load to the wheel. The loaded wheel assembly could be raised and lowered to facilitate sample changes using the compressed air supply of the test machine.

A calibrated Mecmesin advanced single axis force gauge (AFG 1000N, Serial No. 06-031106) was used to measure the minimum horizontal pulling force required to move the floor surface under the wheel. A lanyard was attached between the load hook of the force gauge and the moveable carriage in order to draw the test bed and floor surface under the loaded wheel (Figure 2). This method is based upon an assumption that load is supported equally among the number of wheels, and that actual horizontal force required to move the load can be estimated by multiplying by the number of wheels. The method focuses on the force to initiate movement, which is typically higher than the force needed to continue movement because with static loading the floor material creeps and the wheel sinks further into it.

\subsubsection{Measurements of the horizontal pulling force}

Prior to each measurement, the carriage and floor surface were moved to a predetermined start position. The loaded wheel was lowered onto the floor surface and allowed to rest for a minimum of two minutes prior to a measurement. Samples were allowed a minimum of one- 
hour recovery time before repeat testing. This was deemed a practical time period to account for the hysteretic behaviour of the materials.

The force gauge was held in a position judged to be horizontal and zeroed, without any force applied to the lanyard / carriage. The lanyard was pulled by a single experimenter, gradually building up force until movement was detected by the experimenter. This gives the minimum force required to move the object. For each measurement the force gauge was slowly pulled in a horizontal direction away from the test bed of the machine, so the pulling force was increased slowly and consistently, until the floor surface began to move under the loaded wheel. The peak pulling force measured by the force gauge was recorded. Measurements were repeated three times. This gives the minimum force required to move the object. Measurements were carried out with the castor wheel starting parallel to the direction of the applied pulling force. The horizontal pulling force required to start the carriage moving without the loaded wheel applied was also measured.

\subsubsection{Assessment}

In order to provide an estimate of the force applications for a four wheeled load, such as when pushing / pulling a standard hospital bed with a total weight of $300 \mathrm{~kg}$, we multiplied the test values by four, assuming that the load is evenly distributed between four wheels. The values derived therefore represent situations where all four wheels are initially oriented parallel to the direction of motion [37]. We consider this to represent the best-case situation. The limitations of the test rig prevented other wheel orientation scenarios from being investigated within the current study.

This assessment is based on risk criteria drawn from the Health and Safety Executive's guidance 'L23' on manual handling [38]. L23 guidance provides guideline forces for safe pushing and pulling. Guideline figures to start a load in motion are, for men: $20 \mathrm{~kg}$ (approximately $200 \mathrm{~N}$ ); and for women: $15 \mathrm{~kg}$ (approximately $150 \mathrm{~N}$ ). These guideline forces, which apply for both pushing and pulling operations, assume that the force is applied with both hands, between about waist height and shoulder height enabling a largely upright and symmetrical posture. Our test procedures assess starting a load rather than keeping the load in motion and since the force to keep a load in motion is always less than the starting (or stopping) forces, separate guideline forces are applicable. Further advice on manual handling risk assessment for push-pull activities is available [39].

The following assumptions were made based on the experience the authors have had in a clinical setting. Assessing the clinical application of our findings will vary by setting, as the type of bed in use and typical patient weight will need to be considered as applicable to the local context. For example, the average weight of geriatric rehabilitation patients in France has been estimated at $60 \mathrm{~kg}$ [40], more recently in Egypt a cohort of geriatric patients averaged $76 \mathrm{~kg}$ [41] whilst US data puts the average weight of someone in the general population who is $70+$ years old as $72 \mathrm{~kg}$ [42]. Our selected weight of $300 \mathrm{~kg}$ in the rig set up is therefore compatible with a typical hospital bed weighing 191kg [43] and an adult 70+ years old in the 95th percentile for weight [42].

\subsection{Data Analysis}

A two-tailed Pearson correlation was used to assess the significance of the relationship between impact and horizontal force required to move wheeled objects. To assess how the material type (rubber or not) and material thickness predict impact force attenuation and horizontal pulling forces, a linear regression was calculated for each independent variable, and multiple linear regression incorporating both independent variables, for each dependent variable. Since each floor sample had repeated test measures for horizontal pulling forces ( $n=3$ test runs) and impact ( $n=3$ or 5 test runs), we based our regressions on the mean test 
score for each flooring sample. In all analyses, we set $p<0.05$ as the threshold for statistical significance.

\section{Results}

Considerable differences were identified between floor samples in their ability to reduce the peak impact force during a simulated fall (range $0.69 \%$ to $25.24 \%$ change relative to baseline; absolute difference $-15.45 \mathrm{~N}$ to $-564.4 \mathrm{~N}$ ). A peak force reduction of up to $25 \%$ was achieved with a specially designed rubber underlay compared to $1 \%$ with standard vinyl (Figure 3 ). The $2.0 \mathrm{~mm}$ vinyl floor sample (A-vinyl-2.0) with no foam backing performed the worst; offering little to no reduction (Table 2). Ten out of the fourteen floor samples attenuated the force by $\geq$ $5 \%$, but only one out of the fourteen floor samples attenuated the force by $\geq 20 \%$.

Horizontal pulling forces (maximum force $=85.27 \mathrm{~N}$ for one wheel) increased by $9.42 \%$ to $111.4 \%$ relative to baseline (absolute difference $14.14 \mathrm{~N}$ to $44.94 \mathrm{~N}$ ) for the $2.0 \mathrm{~mm}$ vinyl and $25 \mathrm{~mm}$ thick floor with rubber underlay respectively (Table 2). Our set of floor samples indicated that increased shock-absorbency is not directly associated with increased horizontal pulling forces $(r(15)=-0.087, p=0.759)$, which can be seen clearly in Figure 4. Rubber flooring and thicker flooring together predicted $66.5 \%$ of the variation in horizontal force required to pull a wheel (Adjusted $\mathrm{R}^{2}=0.665, \mathrm{~F}(2,12)=14.92, \mathrm{p}=0.001$ ), and $82.3 \%$ of the variation in impact scores (Adjusted $\left.R^{2}=0.823, F(2,11)=31.20, p<0.001\right)$.

Floor thickness and rubber floors both significantly contributed to the multiple linear regression on horizontal pulling force (both $p<0.001$ ), even though they did not contribute significantly when considered in isolation in simple linear regressions (thickness: $F(1,14)=2.79, p=0.12$, $R^{2}=0.17$; rubber: $\left.F(1,13)=1.44, p=0.25, R^{2}=0.10\right)$. These findings are reflected in Figure 3 , in which the rubber floors (identification codes $\mathrm{G}$ and $\mathrm{N}$ ) produced what appears to be a downward step-change in the otherwise upward trend in horizontal pulling force that is evident from floors of increasing thickness. 'O-rubber-25.0' is the same rubber underlay as ' $\mathrm{N}$-rubber23.0 ' with the addition of a standard vinyl overlay. This floor produced a $111.43 \%$ increase in resistance to wheel movement from baseline, placing it on a par with the thicker foam floors (e.g. L-foam-9.2, which had a $105.48 \%$ increase in resistance).

In our sample, floor thickness better predicted impact reduction (thickness: $F(1,13)=79.77, p$ $<0.001, R^{2}=0.86$; rubber: $F(1,12)=6.66, p=0.02, R^{2}=0.36$ ), with rubber material not contributing to the multiple regression model when looked at in combination with thickness $(p$ $=0.82$ ). However rubber was not universally better than foam-based floors with regards to impact reduction (Figure 3); 'G-rubber-7.0' performed worse on the impact tests when compared to foam floors of lesser thicknesses, whereas the high performance of ' $\mathrm{N}$-rubber23.0' could be attributable to its greater thickness and/or other variables not assessed here (e.g. this underlay has a novel honeycomb structure whereas the rubber backing of sample G-rubber-7.0 is an continuous homogeneous layer).

\section{Discussion}

The range of force attenuation upon impact varied considerably among all floor samples tested $(0.7-25 \%)$. Specially designed rubber flooring with a honeycomb structure performed well in the laboratory, but other floor samples, such as the standard vinyl gave negligible force attenuation, and are likely to provide little to no protection during a fall. It should be noted that there is currently no definitive threshold for the force attenuation required to provide effective prevention against injury. In reality there is unlikely to be a simple threshold due to the variation in bone strength and fall kinematics, and it is probable that any force attenuation will prevent some injuries, but it may be very difficult to prevent all injuries. 
This study has used the same test method for assessing hip protectors (as described in the CSA Standard) to assess the impact properties of a number of commercially available floor samples. These biomechanical testing methods have been previously used to assess the peak force reduction during a simulated fall of eighteen commercially available hip protectors [36]. It is interesting to note that the force attenuation for these hip protectors ranged from $3-36$ $\%$, and in this study the force attenuated by the floor surfaces was $0.7-25 \%$. Whilst the majority of floor surfaces attenuated the force by $\leq 7 \%$, one floor ( $\mathrm{N}$-rubber-23.0) was on a par with the Delloch hip protectors, offering the user a reasonable amount of protection of $\geq$ $20 \%$. By contrast, the Suprima and Bort hip protectors offered little or no protection, similar to the standard vinyl, rubber and foam floors tested in the current study $(\leq 7 \%)$. Perhaps counterintuitively, the floor surfaces offered a similar range of impact protection to the wearable hip protectors, but for both floor materials and hip protectors the choice of product is critical, with some offering little or no protection. As with hip protectors, it is important to test individual floor materials, as the performance depends on many details of the design and it is not possible to draw generic conclusions based for example on thickness or the choice of covering material.

Whilst these results are only applicable to assessing the risk of hip fracture during a simulated fall, it has allowed the force attenuation of both hip protectors and floor coverings to be compared. It has shown that a specially designed floor can provide the same attenuation as a hip protector. As described in the Introduction section, there are advantages and disadvantages with both hip protectors and shock-absorbing flooring. The design and material significantly influence the amount of force attenuated during a fall. Whilst there are concerns regarding user compliance with hip protectors, there are issues regarding the ability and ease in which wheeled equipment can be moved in a hospital, care home or a personal home, whilst still offering protection against an injurious fall [14][44]. The primary difference, however, is that shock-absorbing flooring is passive, and does not require an individual to accept the initial offer of the technology, and to continue to adhere to protocols concerning its use, whilst hip protectors must be worn (correctly) at the time of a fall to offer protection. Furthermore, it can potentially offer protection to multiple vulnerable locations (hip, wrist, head, spine). Therefore, exploring how best to mitigate the risks to people working on shock-absorbing floors, and better determining the clinical effectiveness of shock-absorbing floor coverings through pragmatic studies, is warranted.

Although laboratory testing is an essential first step, the effectiveness of floor materials in reducing injury can only be fully quantified in clinical settings; For example, a novel $25.4 \mathrm{~mm}$ rubber-based health floor with $2 \mathrm{~mm}$ vinyl overlay recently assessed in comparison to a 25.4 $\mathrm{mm}$ plywood underlay with a $2 \mathrm{~mm}$ vinyl overlay resulted in no significant difference in injury rates [18]. We acknowledge that a flooring sample tested to be biomechanically effective in a laboratory setting does not necessarily mean that it would be clinically effective. However, it is fair to say that a material that performs poorly in lab trials is very unlikely to be clinically effective. We strongly recommend conducting mechanical tests to eliminate floor surfaces which are largely ineffective at reducing the peak force before embarking on clinical trials of floor surfaces. This is an important screening step given the high cost and large numbers of subjects needed for such trials.

It is important to note that the mechanical impact testing performed in this study was designed to simulate a sideways fall onto the greater trochanter, and it applies to reducing risk of hip fracture during a fall. Thus, the force attenuation values from the current study represent force attenuation at the hip. Other anatomical body parts subject to injury (such as the head and wrist) could occur from falling forwards or backwards, and the dynamics of these injuries are different, and hence the optimum floor properties to protect against them may also be different. It would therefore be necessary to conduct further testing with a modified test rig to obtain force attenuation at these locations. That said, given the significant consequences of hip fractures with regards to quality of life, morbidity, mortality, and health and social care, which position them as one of the most important fall-related injuries to target for prevention efforts 
[11][12][45][14], it would be logical to focus laboratory testing efforts on the hip model. This may be particularly the case in the context of shock-absorbing flooring targeting environments for older people, for whom hip fracture incidence becomes far more problematic than that of the wrist for example [46]. Although it is important to emphasise that the development of head models should not be disregarded, as the result from impact to the head can also have severe consequences [16].

For some of the floors there was a considerable increase in the horizontal pulling force required for wheel movement. The predicted force needed to pull a bed (assuming all wheels are orientated forwards) ranged from $160 \mathrm{~N}$ (baseline) to $341 \mathrm{~N}$; comparing this to the HSE guideline maximum force of $150 \mathrm{~N}$ for women makes it clear that this could be a significant issue, and evaluation of horizontal push/pull forces is very important when considering protective flooring products. For example, in a study utilising an $8.3 \mathrm{~mm}$ thick foam-backed vinyl, staff considered the resistance to movement to be a problem [27]. One possible solution could be to use larger wheels; ideally the wheels, furniture and floor surfaces should be considered together as a system. Lachance et al., found that novel shock-absorbing flooring increased the initial and sustained forces required to push floor-based lifts and subjective ratings of difficulty compared to concrete flooring, and that compared to a conventional lift, a motor-driven lift substantially reduced initial and sustained push forces and perceived difficulty of pushing for all four floors assessed and both resident weights [34]. It is also interesting to note that other floor constructions, for example suspended wooden flooring, can have a similar level of compliance to the floors tested in this study and have the potential to provide significant protection against fall injuries [47][48]. This approach was traditionally exploited in gymnasiums, for example. By making the whole floor slightly flexible, rather than using a locally shock-absorbing surface, the problem of resistance to wheel movement could be reduced.

In our selection of floor samples, we discovered that there was no simple relationship between impact properties and horizontal pulling forces; Greater shock-absorbency in a floor covering does not necessarily equate to it also being harder to pull wheeled equipment across. Whilst material type and thickness can help predict shock-absorbency and the pulling forces required to move wheel equipment, other (as yet) unknown variables also contribute to these floor performance measures, and it would not be appropriate to try to draw simplistic general conclusions. Together, these findings exemplify the importance of measuring both impact properties and pulling forces for wheel movement when selecting floors for use in practice, as neither can be easily assumed. The implications of this finding additionally exemplify the opportunities for manufacturers and material scientists to design floors that support a better trade-off between reducing fall-related injury risk in patients and increasing musculoskeletal injury risk in staff. Our findings on the influence of rubber should be interpreted with caution since we only had two rubber flooring samples, and one of these was also very thick with a novel structure. Further studies, which systematically assess the influence of a wider range of thicknesses, material types, and other factors (such as material structure) on shockabsorbency and pushing and pulling forces, using standardised test methods, would be beneficial to better understand the determining characteristics of high-performing floors.

Laing and Robinovitch used a pendulum system as described in the CSA Z235 Standard. Our testing uses the alternative drop tower impact system (also described in the Standard) [36][31]. This study presents results which will be useful for manufacturers or researches who have this type of rig available. A future biomechanical study could compare the force attenuation between the two impact systems (pendulum and drop tower) to see what, if any, variation is present when biomechanically testing shock-absorbing flooring. Standardisation of test methods is paramount if we are to progress this field. In a study comparing impact forces and wheelchair mobility of various floor coverings [24], in which force attenuation was measured by dropping a manikin on to its knees to simulate a fall, baseline readings far exceeded the forces measured in the present study, exerting approximately $12132 \mathrm{~N}$. The manikin test 
method [24] resulted in impact force measurements of $10622 \mathrm{~N}$ for a $5 \mathrm{~mm}$ vinyl, $10326 \mathrm{~N}$ for a $6.3 \mathrm{~mm}$ vinyl, and $10553 \mathrm{~N}$ for an $8.3 \mathrm{~mm}$ vinyl respectively (mean differences exceeding $1500 \mathrm{~N}$ ). Conversely, the wheel movement testing measurements, captured via wheelchair propulsion forces, were somewhat lower (baseline forces approximately $25.65 \mathrm{~N}$ ) than found using our test rig method, which are likely attributable in part to the larger wheels of a wheelchair. Other impact force test methods have included using a sling and electromagnet to raise and drop the hips of young female adults on to floor surfaces of varying stiffnesses [25], an impact transducer dropped through a plastic tube [28], a drop rig with hip model [30], an impact pendulum with surrogate pelvis including simulated soft tissue [23], and an inverted pendulum model with an aluminium hip impactor [29]. This vast range of impact test methods, and different types or categories of flooring makes objective comparison difficult. For example: Gardner et al., uses a weight which corresponds to one-sixteenth of an average body mass, hence the results for peak force are much lower than what we have reported in this study [28]. Gardner, Minns and Maki all test carpet and/or concrete which was not tested in the present study [28][29][30]. However, the values in our study for two floor types are consistent with the findings from Laing and Robinovitch, where our vinyl 'rigid' layer of $0.7 \%$ force attenuation offers no protection and our novel rubber floor of $25 \%$ is consistent with $22.5 \%$ at $3 \mathrm{~m} / \mathrm{s}$ [23].

To date, resistance to wheel movement has typically been measured using everyday equipment, such as wheelchairs [17][44], or a four-wheeled cart [37]. These test methods require space, large amounts of test materials, and can lack the standardisation that a test rig affords. Our testing procedure for pulling forces only considered the peak force required to initiate movement, which is always going to be higher than the sustained forces required to continue movement. We considered this metric more pertinent since mechanical assistance and multiple persons are more likely to be involved in moving heavy objects further distances, in line with health and safety guidelines, whereas anecdotal evidence suggests that staff may operate in isolation to perform brief movement tasks (such as for cleaning or to pull a bed away from a wall to fully access a patient in an emergency) [32][33]. However, we acknowledge that sustained forcesalso have an important role to play in injury risk prevention, and exposure to these types of forces can occur over longer durations. Our testing procedures have scope for further enhancements, for example with consensus building around the load choice and standardising the pulling task through for example a mechanical arm. We are advocating for the establishment of recognised testing standards for floor surfaces designed for fall-related injury prevention to enable future findings to be wholly comparable. Our findings suggest that our proposed test methods can be reasonably used to characterise and distinguish between different floor surfaces and offer a standardised technique for impact testing which aligns with consensus for characterising hip protectors.

In conclusion, this study used two tests to assess the protection a shock-absorbing floor can offer over conventional vinyl flooring in the event of a fall. We hope that these results can inform the establishment of standards needed to underpin practice, research, and development in this field.

\section{Conflicts of Interests}

Dr Drahota and Dr Keenan are currently working on a systematic review entitled 'The SAFEST Review: The Shock-Absorbing Flooring Effectiveness SysTematic Review including older adults and staff in care settings' funded by the National Institute for Health Research $(17 / 148 / 11)$. The present laboratory study is ineligible for inclusion in this review of human participant data.

In 2015, Dr Drahota was involved in a collaborative funding application with Polyflor for some SBRI Healthcare innovation funding. The application was short-listed but unsuccessful. AD has no stake in this company. 
Five flooring manufacturers delivered free samples to use in this exploratory project, some of which were supplied in confidence because they are not designed for this purpose. The authors have no stake in any of these companies.

Mr Hallas has undertaken unrelated testing work for the flooring manufacturer Polyflor under contract with the Health and Safety Executive and related resistance to wheel movement testing for the flooring manufacturer Tarkett under contract with the Health and Safety Executive.

Prof Evans is involved in the Technical Committee on Hip Protectors for the CSA Z325 standard.

Dr Keenan and Prof Evans have previously undertaken commercial testing of hip protectors which is referenced in this paper but have no conflicts of interest for the work presented here.

\section{References}

1. World Health Organisation (2018) Falls. https://www.who.int/news-room/factsheets/detail/falls

2. Kannus P, Parkkari J, Sievänen H, et al (1996) Epidemiology of hip fractures. In: Bone. pp 18:57S-63S

3. Lauritzen JB (1996) Hip fractures: Incidence, risk factors, energy absorption, and prevention. In: Bone. pp 18:65S-75S

4. Stevens JA (2005) Falls among older adults-risk factors and prevention strategies. J Safety Res. https://doi.org/10.1016/j.jsr.2005.08.001

5. Benzinger $P$, Riem S, Bauer J, et al (2019) Risk of institutionalization following fragility fractures in older people. Osteoporos Int. https://doi.org/10.1007/s00198-019-04922-x

6. Empana JP, Dargent-Molina P, Bréart G (2004) Effect of Hip Fracture on Mortality in Elderly Women: The EPIDOS Prospective Study. J Am Geriatr Soc. https://doi.org/10.1111/j.1532-5415.2004.52203.x

7. Kanis JA (2007) WHO Scientific Group Technical Report: Assessment of osteoporosis at the primary health care level. Univ Sheff

8. Melton LJ, Chrischilles EA, Cooper C, et al (1992) Perspective how many women have osteoporosis? J Bone Miner Res. https://doi.org/10.1002/jbmr.5650070902

9. Compston J, Bowring C, Cooper A, et al (2013) Diagnosis and management of osteoporosis in postmenopausal women and older men in the UK: National Osteoporosis Guideline Group (NOGG) update 2013. Maturitas. https://doi.org/10.1016/j.maturitas.2013.05.013

10. Public Health England (2017) Falls: applying All Our Health. In: Guid. Pap.

11. Gullberg B, Johnell O, Kanis JA (1997) World-wide projections for hip fracture. Osteoporos Int. https://doi.org/10.1007/PL00004148

12. Svedbom A, Hernlund E, Ivergård M, et al (2013) Osteoporosis in the European Union: A compendium of country-specific reports. Arch Osteoporos. https://doi.org/10.1007/s11657-013-0137-0

13. Morello RT, Barker AL, Watts JJ, et al (2015) The extra resource burden of in-hospital falls: A cost of falls study. Med J Aust. https://doi.org/10.5694/mja15.00296 
14. Santesso N, Carrasco-Labra A, Brignardello-Petersen R (2014) Hip protectors for preventing hip fractures in older people. Cochrane Database Syst. Rev.

15. Korall AMB, Feldman F, Yang Y, et al (2019) Effectiveness of Hip Protectors to Reduce Risk for Hip Fracture from Falls in Long-Term Care. J Am Med Dir Assoc. https://doi.org/10.1016/j.jamda.2019.07.010

16. Schonnop R, Yang Y, Feldman F, et al (2013) Prevalence of and factors associated with head impact during falls in older adults in long-term care. CMAJ. https://doi.org/10.1503/cmaj.130498

17. Lachance CC, Jurkowski MP, Dymarz AC, et al (2017) Compliant flooring to prevent fall-related injuries in older adults: A scoping review of biomechanical efficacy, clinical effectiveness, cost-effectiveness, and workplace safety. PLoS One

18. Mackey DC, Lachance CC, Wang PT, et al (2019) The flooring for injury prevention (FLIP) study of compliant flooring for the prevention of fall-related injuries in long-term care: A randomized trial. PLoS Med. https://doi.org/10.1371/journal.pmed.1002843

19. Hanger HC (2017) Low-Impact Flooring: Does It Reduce Fall-Related Injuries? J Am Med Dir Assoc. https://doi.org/10.1016/j.jamda.2017.01.012

20. Drahota A, Felix LM, Keenan BE, et al (2020) Protocol for the SAFEST review: The Shock-Absorbing Flooring Effectiveness SysTematic review including older adults and staff in hospitals and care homes. BMJ Open

21. Wright AD, Heckman GA, Mcllroy WE, Laing AC (2014) Novel safety floors do not influence early compensatory balance reactions in older adults. Gait Posture. https://doi.org/10.1016/j.gaitpost.2014.03.015

22. Wright $A D$, Laing $A C$ (2011) The influence of novel compliant floors on balance control in elderly women - A biomechanical study. Accid Anal Prev. https://doi.org/10.1016/j.aap.2011.02.028

23. Laing AC, Robinovitch SN (2009) Low stiffness floors can attenuate fall-related femoral impact forces by up to $50 \%$ without substantially impairing balance in older women. Accid Anal Prev. https://doi.org/10.1016/j.aap.2009.03.001

24. Hales M, Johnson JD, Asbury G, Evans N (2015) Influence of floor covering composition on force attenuation during falls, wheelchair mobility, and slip resistance. AATCC Rev. https://doi.org/10.14504/ar.15.6.4

25. Laing AC, Tootoonchi I, Hulme PA, Robinovitch SN (2006) Effect of compliant flooring on impact force during falls on the hip. J Orthop Res. https://doi.org/10.1002/jor.20172

26. Wright $A D$, Laing $A C$ (2012) The influence of headform orientation and flooring systems on impact dynamics during simulated fall-related head impacts. Med Eng Phys. https://doi.org/10.1016/j.medengphy.2011.11.012

27. Laing AC, Robinovitch SN (2008) The force attenuation provided by hip protectors depends on impact velocity, pelvic size, and soft tissue stiffness. J Biomech Eng. https://doi.org/10.1115/1.2979867

28. Gardner TN, Simpson AHRW, Booth C, et al (1998) Measurement of impact force, simulation of fall and hip fracture. Med Eng Phys. https://doi.org/10.1016/S13504533(97)00041-6

29. Maki BE, Fernie GR (1990) Impact attenuation of floor coverings in simulated falling accidents. Appl Ergon. https://doi.org/10.1016/0003-6870(90)90132-H

30. Minns J, Nabhani F, Bamford JS (2004) Can flooring and underlay materials reduce 
hip fractures in older people? Nurs Older People.

https://doi.org/10.7748/nop2004.07.16.5.16.c2320

31. Canadian Standards Association (2020) Z325:20 Hip Protectors. In: CSA Gr. https://store.csagroup.org/ccrz__ProductDetails?viewState=DetailView\&cartID=\&port alUser $=\&$ store $=\&$ cclcl=en_US\&sku=CSA Z325\%3A20\&format=PDF

32. Drahota AK, Kward D, Udell JE, et al (2013) Pilot cluster randomised controlled trial of flooring to reduce injuries from falls in wards for older people. Age Ageing. https://doi.org/10.1093/ageing/aft067

33. Wynn T, Riley D H-RJ (2011) Ergonomics appraisal of the manual handling (pushpull) risk factors in areas using impact absorbing flooring (HuSU/11/13)

34. Lachance CC, Korall AMB, Russell CM, et al (2018) Hand forces exerted by long-term care staff when pushing wheelchairs on compliant and non-compliant flooring. Appl Ergon. https://doi.org/10.1016/j.apergo.2018.04.009

35. Lachance CC, Korall AMB, Russell CM, et al (2016) External Hand Forces Exerted by Long-Term Care Staff to Push Floor-Based Lifts: Effects of Flooring System and Resident Weight. Hum Factors. https://doi.org/10.1177/0018720816644083

36. Keenan BE, Evans SL (2019) Biomechanical testing of hip protectors following the Canadian Standards Association express document. Osteoporos Int. https://doi.org/10.1007/s00198-019-04914-x

37. Al-Eisawi KW, Kerk CJ, Congleton JJ, et al (1999) Factors affecting minimum push and pull forces of manual carts. Appl Ergon. https://doi.org/10.1016/S00036870(98)00019-2

38. Health and Safety Executive (2016) Manual handling: Manual Handling Operations Regulations 1992. L23 (Fourth edition). Regulation

39. Health and Safety Executive (2016) Risk Assessment of pushing and pulling (RAPP) tool. http://www.hse.gov.uk/pubns/indg478.pdf \%0A

40. Bouillanne O, Morineau G, Dupant C, et al (2005) Geriatric Nutritional Risk Index: A new index for evaluating at-risk elderly medical patients. Am J Clin Nutr 82:777-783. https://doi.org/10.1093/ajcn/82.4.777

41. Rasheedy D, El-Kawaly WH (2020) The accuracy of the Geriatric Nutritional Risk Index in detecting frailty and sarcopenia in hospitalized older adults. Aging Clin Exp Res. https://doi.org/10.1007/s40520-020-01492-5

42. Fryar CDC, Gu Q, Ogden CL, et al (2010) Anthropometric Reference Data for Children and Adults: United States ,. Vital Heal Stat 11:2007-2010

43. Park SJ, Kim CB, Park SC (1999) Anthropometric and biomechanical characteristics on body segments of Koreans. J Physiol Anthropol Appl Human Sci. https://doi.org/10.2114/jpa.18.91

44. Minns J, Tracey S (2011) Wheelchair pushing forces over a vinyl and a new shockabsorbing flooring. Br J Occup Ther. https://doi.org/10.4276/030802211X12947686093684

45. R.T. M, A.L. B, J.J. W, et al (2015) The extra resource burden of in-hospital falls: A cost of falls study. Med. J. Aust.

46. Riggs BL, Melton LJ, Robb RA, et al (2006) Population-based analysis of the relationship of whole bone strength indices and fall-related loads to age- and sexspecific patterns of hip and wrist fractures. J Bone Miner Res. 
https://doi.org/10.1359/JBMR.051022

47. Shields BJ, Smith GA (2009) The potential for brain injury on selected surfaces used by cheerleaders. J Athl Train. https://doi.org/10.4085/1062-6050-44.6.595

48. Rajaei N, Abdolshah S, Akiyama Y, et al (2018) Rigid Material on Top of a Compliant Flooring Effectively Reduces the Impact Force in the Event of a Forward Fall. In: 2018 International Conference on Intelligence and Safety for Robotics, ISR 2018

\section{Authors' Contributions}

All authors were involved in the study and preparation of the manuscript. The material within has not been and will not be submitted for publication elsewhere. Authors' contributions are as follows: SLE and BEK designed the study. BEK designed the mould, made the silicone and conducted the mechanical impact testing. KH conducted the push/pull testing. SLE, BEK, AKD and $\mathrm{KH}$ analysed the data. BEK and AKD prepared the manuscript. All authors read and approved the final manuscript.

\section{Acknowledgements}

We would like to thank the flooring manufacturers who provided test samples for use in this project. Thank you to Mr Ngianga Kandala who provided statistical support and review of this manuscript.

\section{Disclaimer}

This publication and the work it describes were co-funded by the Cardiff University, the University of Portsmouth and the Health and Safety Executive. Its contents, including any opinions and/or conclusions expressed, are those of the authors alone and do not necessarily reflect HSE policy.

\section{Figure Captions}

Figure 1: Test set-up showing drop-weight assembly with soft tissue simulant placed directly over femur form (left) and aluminium proximal femur form attached to base of drop tower (right).

Figure 2: Wheel movement force test set-up. The single axis force gauge and lanyard are attached to the test bed and an arrow shows the direction of application of the pulling force.

Figure 3: Percentage reduction in peak force from mechanical impact testing and horizontal pulling force with error bars (+/- 1SE).

Figure 4: Relationship between impact force attenuation and mean horizontal pulling force (+/- 1SE).

Figure 5: Examples of force-time graphs for the best and worst performing floors produced in Matlab (specially designed rubber floor vs standard vinyl). Where raw data is shown in blue and filtered data is shown in orange using a low-pass fourth-order Butterworth. 


\section{Table Captions}

Table 1: Floor sample codes with product description and thickness.

Table 2: The mean, range, and difference in means from baseline for both the peak force attenuation and single wheel movement for the fourteen floor samples tested. 


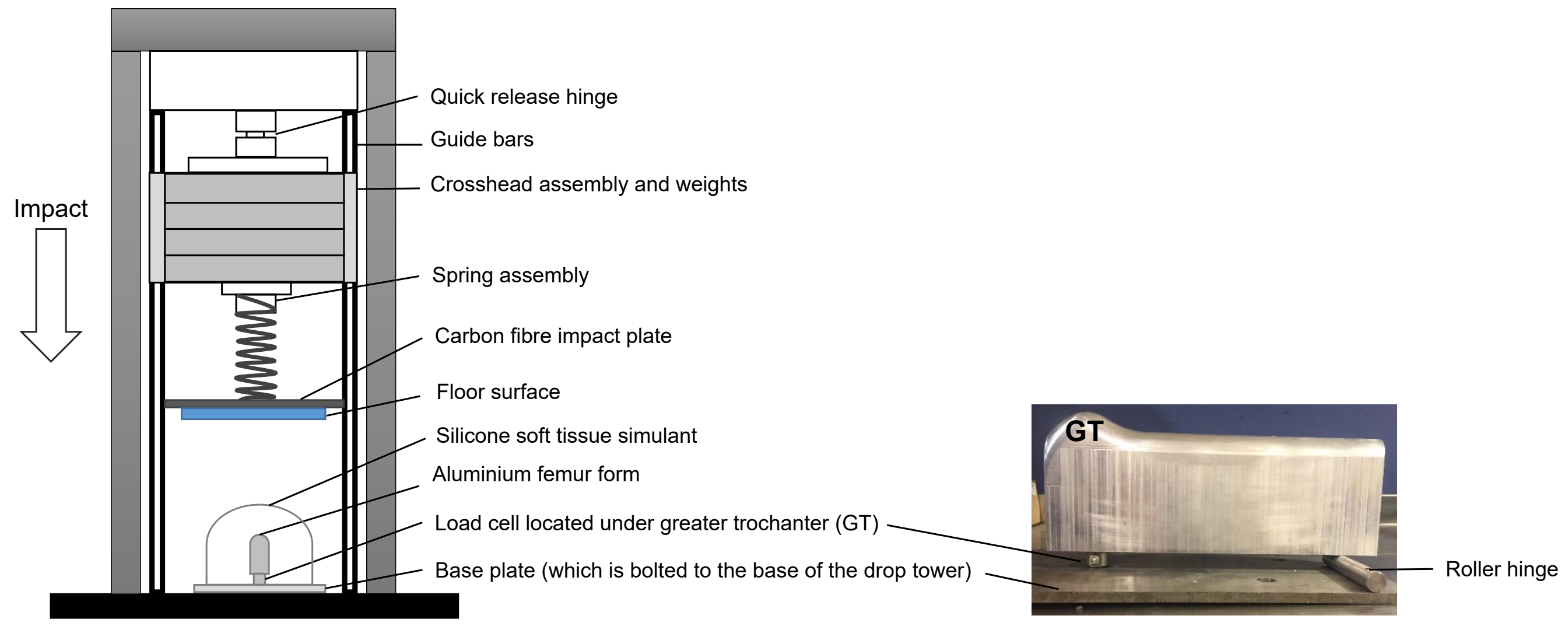




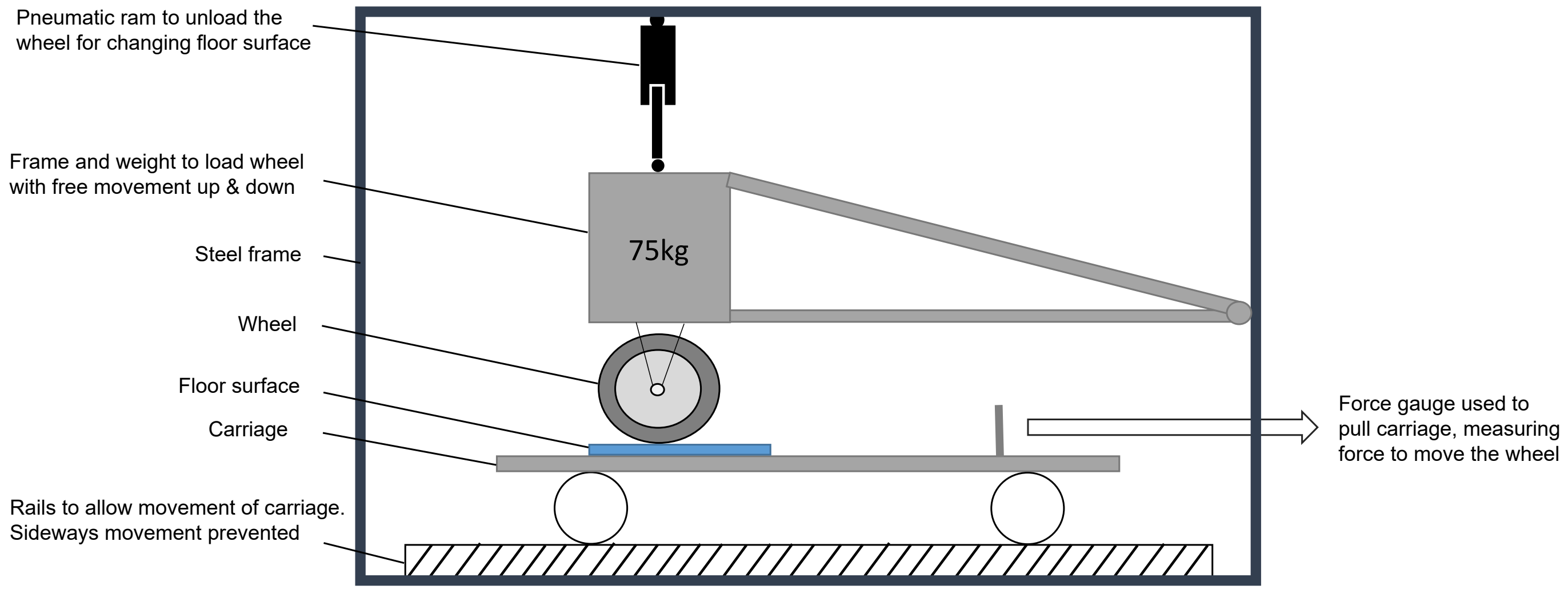




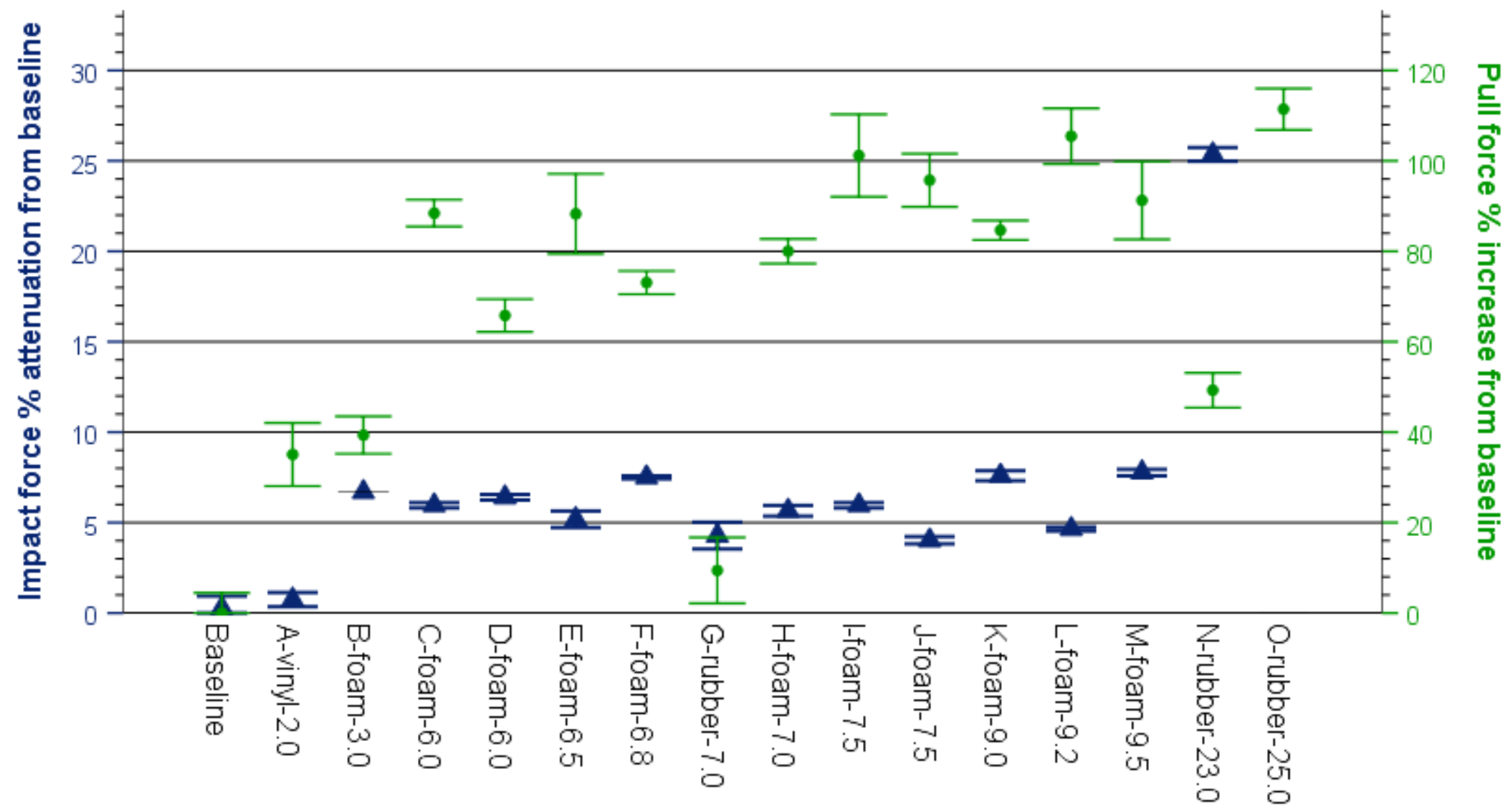

Floor sample (ID-material-thickness)

Markers and error bars: mean $+/-1 \mathrm{SE}$; blue triangles = impact force, green circles = pull force . 


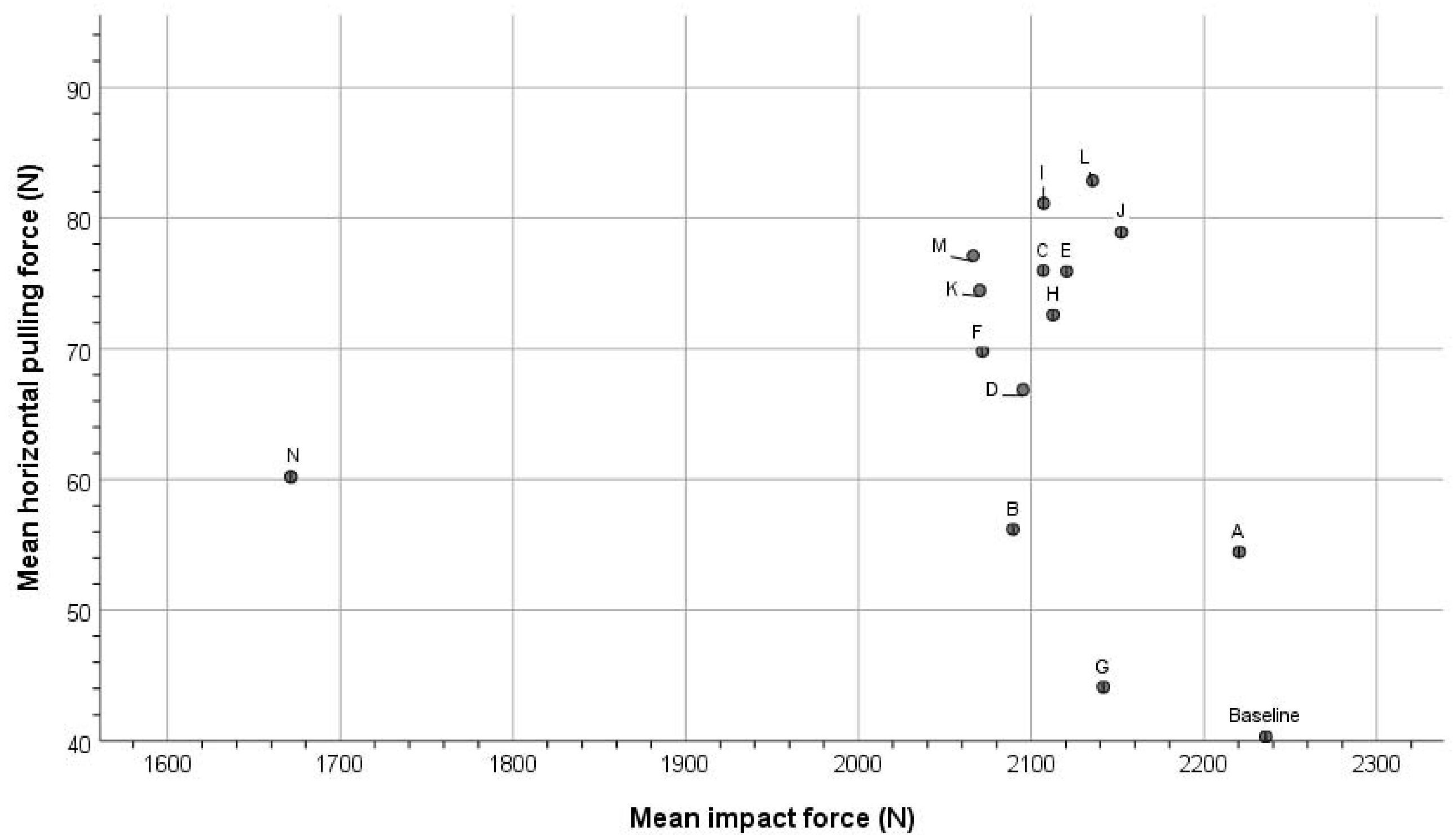

Data points are labelled with the flooring identification code (Baseline, $A-N$ ) 
Floor ID A-vinyl-2.0

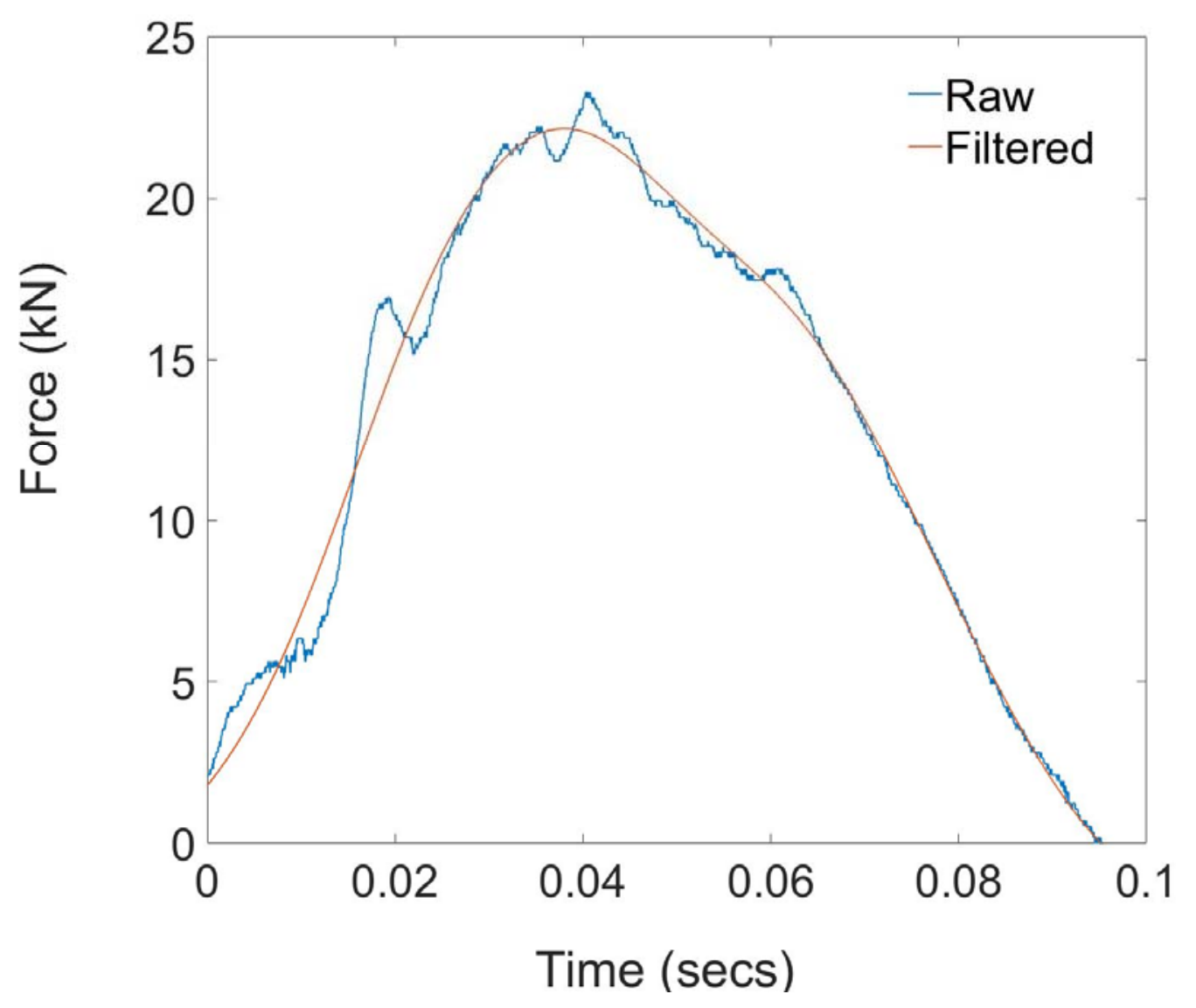

Floor ID N-rubber-23

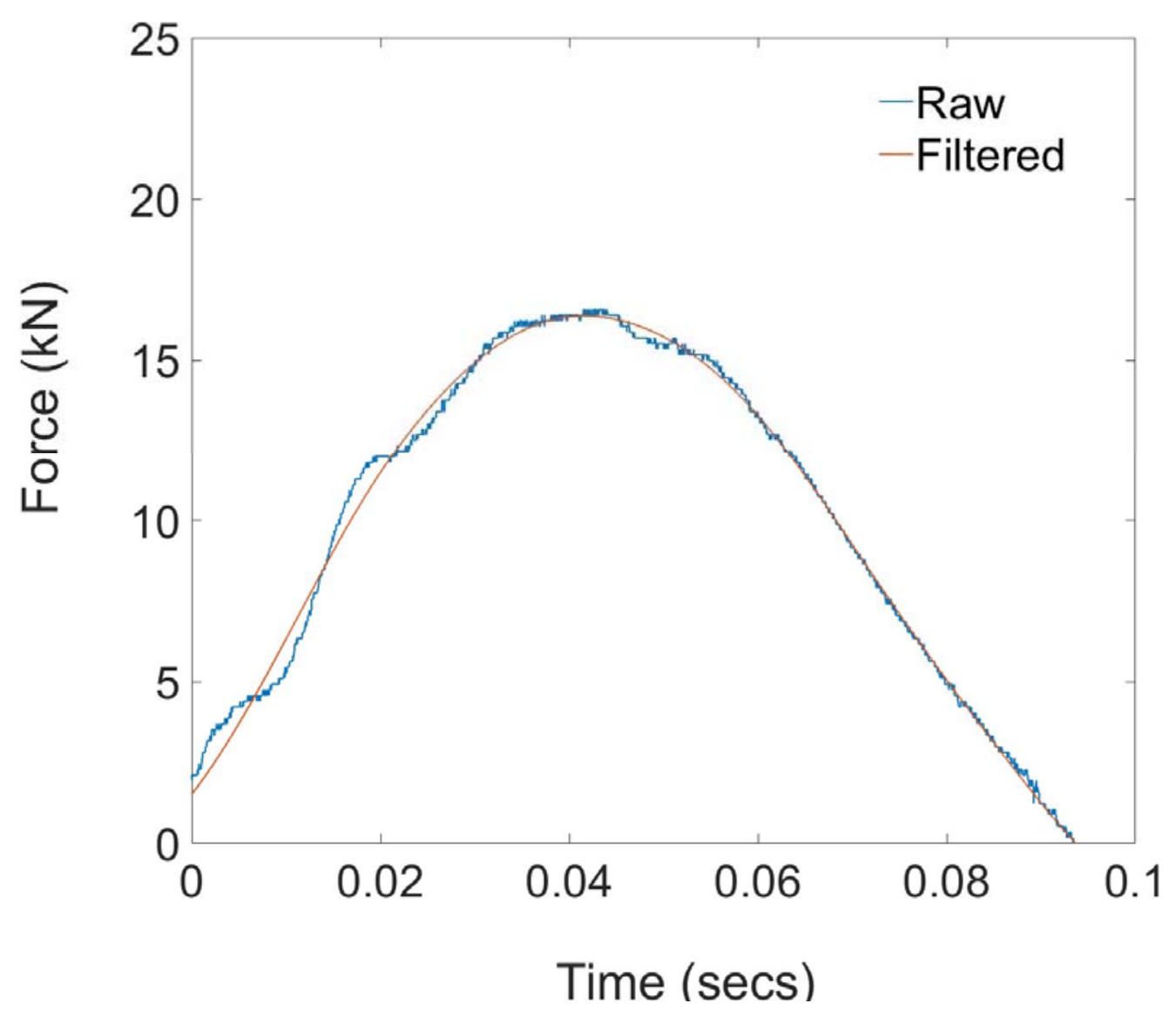




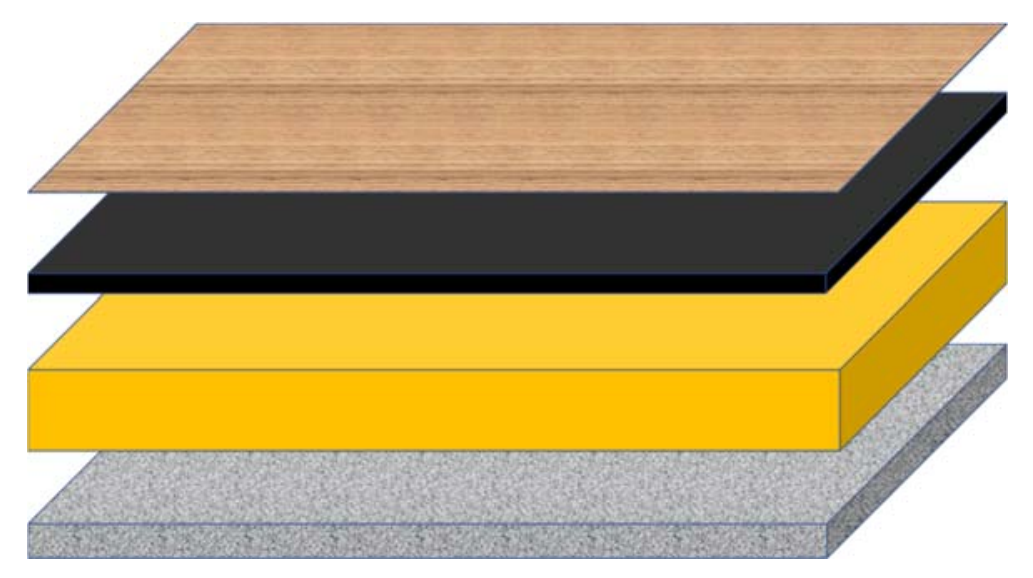

\section{Surface Layer}

\section{Rigid Layer}

Underlay Layer 1

Underlay Layer 2

\begin{tabular}{|c|c|c|c|c|c|c|}
\hline \multirow[b]{2}{*}{ Floor ID } & \multirow[b]{2}{*}{ Product Description } & \multicolumn{5}{|c|}{ Thickness of each layer (mm) } \\
\hline & & $\begin{array}{c}\text { Surface } \\
\text { layer }\end{array}$ & $\begin{array}{c}\text { Rigid } \\
\text { layer/glue }\end{array}$ & $\begin{array}{c}\text { Underlay } \\
\text { layer } 1\end{array}$ & $\begin{array}{c}\text { Underlay } \\
\text { layer } 2\end{array}$ & $\begin{array}{c}\text { Overall } \\
\text { thickness }\end{array}$ \\
\hline A-vinyl-2.0 & Standard vinyl & 2.0 & $\mathrm{X}$ & $\mathrm{X}$ & $\mathrm{X}$ & 2.0 \\
\hline B-foam-3.0 & Foam-back vinyl & 0.7 & 0.3 & 2.0 & $\mathrm{X}$ & 3.0 \\
\hline C-foam-6.0 & Foam-back vinyl & 0.7 & 1.3 & 4.0 & $\mathrm{X}$ & 6.0 \\
\hline D-foam-6.0 & Foam-back vinyl & 1.5 & 0.5 & 4.0 & $\mathrm{X}$ & 6.0 \\
\hline E-foam-6.5 & Foam-back vinyl & 0.4 & 0.1 & 3.0 & 3.0 & 6.5 \\
\hline F-foam-6.8 & Foam-back vinyl & 2.0 & 0.3 & 1.5 & 3.0 & 6.8 \\
\hline G-rubber-7.0 & Rubber-backed vinyl & 1.0 & 1.0 & 5.0 & $\mathrm{X}$ & 7.0 \\
\hline H-foam-7.0 & Foam-backed vinyl & 1.5 & 0.5 & 2.5 & 2.5 & 7.0 \\
\hline l-foam-7.5 & Foam-backed vinyl & 0.5 & 1.0 & 3.0 & 3.0 & 7.5 \\
\hline J-foam-7.5 & Foam-backed vinyl & 0.5 & 1.0 & 3.5 & 2.5 & 7.5 \\
\hline K-foam-9.0 & Foam-backed vinyl & 1.5 & 0.5 & 3.0 & 4.0 & 9.0 \\
\hline L-foam-9.2 & Foam-backed vinyl & 1.0 & 1.5 & 6.7 & $\mathrm{X}$ & 9.2 \\
\hline M-foam-9.5 & Foam-backed vinyl & 2.0 & 0.5 & 4.0 & 3.0 & 9.5 \\
\hline N-rubber-23.0 & Novelty health floor rubber underlay with no overlay & $\mathrm{X}$ & $\mathrm{X}$ & 23.0 & $\mathrm{X}$ & 23.0 \\
\hline O-rubber-25.0 & Novelty health floor rubber underlay with standard vinyl & 2.0 & $\mathrm{X}$ & 23.0 & $\mathrm{X}$ & 25.0 \\
\hline
\end{tabular}




\begin{tabular}{|c|c|c|c|c|c|c|}
\hline \multirow{2}{*}{ Floor ID } & \multicolumn{3}{|c|}{ Impact } & \multicolumn{3}{|c|}{ Wheel movement } \\
\hline & $\begin{array}{c}\text { Mean peak force } \\
\text { N (SD) }\end{array}$ & $\begin{array}{l}\text { Range of peak force } \\
\text { (N) }\end{array}$ & $\begin{array}{l}\text { Difference in means } \\
\text { from baseline (N) }\end{array}$ & $\begin{array}{c}\text { Mean peak force } \\
\text { N (SD) }\end{array}$ & $\begin{array}{l}\text { Range of peak force } \\
\text { (N) }\end{array}$ & $\begin{array}{l}\text { Difference in means } \\
\text { from baseline }(N)\end{array}$ \\
\hline Baseline/Empty Carriage & $2235.78(34.65)$ & $2207.50-2293.70$ & $\mathrm{n} / \mathrm{a}$ & $40.33(3.11)$ & $37.80-43.80$ & $\mathrm{n} / \mathrm{a}$ \\
\hline A-vinyl-2.0 & $2220.33(15.60)$ & $2207.80-2237.80$ & -15.45 & $54.47(4.88)$ & $49.00-58.40$ & 14.14 \\
\hline B-foam-3.0 & $2089.46(3.31)$ & $2086.30-2094.90$ & -146.32 & $56.20(2.88)$ & $53.80-59.40$ & 15.87 \\
\hline C-foam- 6.0 & $2106.87(8.13)$ & $2097.70-2113.20$ & -128.91 & $76.00(2.08)$ & $74.80-78.40$ & 35.67 \\
\hline D-foam-6.0 & $2095.27(7.45)$ & $2060.30-2065.90$ & -140.51 & $66.87(2.53)$ & $64.00-68.80$ & 26.54 \\
\hline E-foam-6.5 & $2120.46(24.21)$ & $2095.50-2149.20$ & -115.32 & $75.93(6.18)$ & $68.80-79.60$ & 35.6 \\
\hline F-foam-6.8 & $2071.68(4.21)$ & $2066.50-2078.20$ & -164.1 & $69.80(1.80)$ & $68.00-71.60$ & 29.47 \\
\hline G-rubber-7.0 & $2141.72(34.90)$ & $2090.70-2167.80$ & -94.06 & $44.13(5.08)$ & $41.00-50.00$ & 3.8 \\
\hline H-foam-7.0 & $2112.60(15.34)$ & $2095.00-2123.10$ & -123.18 & $72.60(1.91)$ & $71.40-74.80$ & 32.27 \\
\hline I-foam-7.5 & $2107.10(2.98)$ & $2104.40-2110.30$ & -128.68 & $81.13(6.38)$ & $75.40-88.00$ & 40.8 \\
\hline J-foam-7.5 & $2152.14(9.64)$ & $2144.50-2163.40$ & -83.64 & $78.93(4.11)$ & $74.40-82.40$ & 38.6 \\
\hline K-foam-9.0 & $2070.22(14.93)$ & $2058.40-2090.90$ & -165.56 & $74.47(1.50)$ & $73.60-76.20$ & 34.14 \\
\hline L-foam-9.2 & $2135.48(5.17)$ & $2127.70-2139.30$ & -100.3 & $82.87(4.31)$ & $78.40-87.00$ & 42.54 \\
\hline M-foam-9.5 & $2066.32(8.11)$ & $2058.30-2076.40$ & -169.46 & $77.13(6.01)$ & $72.80-84.00$ & 36.8 \\
\hline N-rubber-23.0 & $1671.38(20.28)$ & $1638.00-1689.70$ & -564.4 & $60.20(2.69)$ & $57.20-62.40$ & 19.87 \\
\hline O-rubber-25.0 & Not measured & $x$ & $x$ & $85.27(3.20)$ & $82.00-88.40$ & 44.94 \\
\hline
\end{tabular}

